\title{
An optimal transition time to extracorporeal cardiopulmonary resuscitation for predicting good neurological outcome in patients with out-of-hospital cardiac arrest: a propensity-matched study
}

Su Jin $\mathrm{Kim}^{1+}$, Jae Seung Jung ${ }^{2+}$, Jae Hyoung Park ${ }^{3}$, Jong Su Park', Yun Sik Hong ${ }^{1}$ and Sung Woo Lee ${ }^{1 *}$

\begin{abstract}
Introduction: Prolonged conventional cardiopulmonary resuscitation (CCPR) is associated with a poor prognosis in out-of-hospital cardiac arrest (OHCA) patients. Alternative methods can be needed to improve the outcome in patients with prolonged CCPR and extracorporeal cardiopulmonary resuscitation (ECPR) can be considered as an alternative method. The objectives of this study were to estimate the optimal duration of CPR to consider ECPR as an alternative resuscitation method in patients with CCPR, and to find the indications for predicting good neurologic outcome in OHCA patients who received ECPR.
\end{abstract}

Methods: This study is a retrospective analysis based on a prospective cohort. We included patients $\geq 18$ years of age without suspected or confirmed trauma and who experienced an OHCA from May 2006 to December 2013. First, we determined the appropriate cut-off duration for CPR based on the discrimination of good and poor neurological outcomes in the patients who received only CCPR, and then we compared the outcome between the CCPR group and ECPR group by using propensity score matching. Second, we compared CPR related data according to the neurologic outcome in matched ECPR group.

Results: Of 499 patients suitable for inclusion, 444 and 55 patients were enrolled in the CCPR and ECPR group, respectively. The predicted duration for a favorable neurologic outcome $(C P C 1,2)$ is $<21$ minutes of CPR in only CCPR patients. The matched ECPR group with $\geq 21$ minutes of CPR duration had a more favorable neurological outcome than the matched CCPR group at 3 months post-arrest. In matched ECPR group, younger age, witnessed arrest without initial asystole rhythm, early achievement of mean arterial pressure $\geq 60 \mathrm{mmHg}$, low rate of ECPR-related complications, and therapeutic hypothermia were significant factors for expecting good neurologic outcome.

Conclusions: ECPR should be considered as an alternative method for attaining good neurological outcomes in OHCA patients who required prolonged CPR, especially of $\geq 21$ minutes. Younger or witnessed arrest patients without initial asystole were good candidates for ECPR. After implantation of ECPR, early hemodynamic stabilization, prevention of ECPR-related complications, and application of therapeutic hypothermia may improve the neurological outcome.

\footnotetext{
* Correspondence: kuedlee@korea.ac.kr

${ }^{\dagger}$ Equal contributors

'Department of Emergency Medicine, College of Medicine, Korea University,

Inchon-ro 73, Seongbuk-gu, Seoul 136-705, Korea

Full list of author information is available at the end of the article
} 


\section{Introduction}

The survival rate to discharge of out-of-hospital cardiac arrest (OHCA) patients remains poor, despite decades of advanced practice in conventional cardiopulmonary resuscitation (CCPR) [1-5]. The causes of high mortality in OHCA are the failure to establish a return of spontaneous circulation (ROSC) and multiple organ failure, including hypoxic brain injury in patients receiving CCPR [6]. The rate of favorable neurological outcomes in OHCA patients decreases according to the prolongation of CPR duration [1]. Therefore, alternative resuscitative methods may be necessary to improve survival, especially in patients who require prolonged CPR [7].

The American Heart Association (AHA) recommended the classification of extracorporeal cardiopulmonary resuscitation (ECPR) as an alternative method for patients who have a brief no-flow time and a reversible cause of cardiac arrest as Class IIb $[8,9]$. ECPR used as treatment of cardiac arrest may preserve myocardial viability by enhancing coronary blood flow, thus increasing the chance of ROSC [10]. As ECPR provides sufficient perfusion to vital organs such as the brain and the injured myocardium, the window of the duration of effective resuscitation could be extended when using ECPR [11]. In addition, ECPR may increase long-term survival by ensuring adequate oxygenated blood delivery to end organs until an effective cardiac output has been recovered, thus preventing organ failure.

There are few studies on the optimal time to consider alternative resuscitation methods in OHCA patients who receive prolonged CPR. Moreover, the advantage of ECPR as an alternative method for attaining a good cerebral performance category $(\mathrm{CPC})$ score in OHCA patients compared to CCPR is not well known.

We hypothesized that alternative methods may be considered after the optimal cutoff time due to the decreasing rate of good neurological outcomes according to a prolonged duration of CPR. Additionally, after the estimated cutoff time, an effective alternative method, such as ECPR compared to CCPR, may show better neurological outcomes. The primary goal of this study was to estimate the optimal duration of CPR to consider ECPR as an alternative resuscitation method in patients with CCPR, and to determine whether ECPR results in better neurological outcomes than CCPR in patients who require prolonged CPR beyond the optimal duration in OHCA patients. The second goal was to find the indications for predicting good neurologic outcome in patients who receive ECLS.

\section{Materials and methods}

\section{Design and setting}

This study was a retrospective analysis based on a prospective cohort study that was conducted at the emergency department (ED) of the Korea University Medical
Center (KUMC), comprising 44 beds of the 890-bed university teaching hospital, from May 2006 to December 2013. We analyzed the CPR registry that comprised prospectively collected data on pre- and in-hospital variables of cardiac arrest patients who received CPR. The Institutional Review Board (IRB) of KUMC approved the data collection for the establishment of the CPR cohort and informed consent for the CPR cohort and for ECPR was also obtained prior to or after the institution of ECPR, from the families of all cardiac arrest patients, respectively. The IRB of KUMC approved this retrospective analysis separately from establishment of the cohort.

\section{Data collection of the CPR registry}

A CPR coordinator prospectively collected data for the CPR registry according to the Utstein style guideline [12]. The registry included demographic data; comorbidities; whether the cardiac arrest was witnessed; the incidence of suspected or confirmed trauma; presumed time of cardiac arrest; presence of bystander CPR; first documented cardiac arrest rhythm by the emergency medical service (EMS) provider; any return of spontaneous circulation (ROSC); presence of ECPR; the presence of return of spontaneous heart beating (ROSB) after ECPR; presumed cause of cardiac arrest; application of therapeutic hypothermia, coronary angiography (CAG), or percutaneous coronary intervention (PCI); 24-hour survival; the presence of ROSC for $\geq 20$ minutes, hospital length of stay (LOS) in survivors at discharge; CPC score at discharge and 3 months post cardiac arrest; and the final diagnosis at discharge. The CPC score at 3-months post cardiac arrest was obtained from outpatient clinic medical record review and telephone interviews conducted by the $\mathrm{CPR}$ coordinator.

The comorbidity score was calculated using the Charlson comorbidity index [13]. The time intervals were calculated from the registry. The interval between cardiac arrest and start of CPR was defined as the time from when the arrest was witnessed or found, to CPR started by EMS providers, and the CPR duration was defined as the time interval from the first chest compression provided by EMS providers to the termination of resuscitation efforts either because of ROSC (for $\geq 20$ minutes), implantation of ECPR, or declaration of death [14]. If an OHCA patient had recurrent cardiac arrest after gaining ROSC (for $\geq 20$ minutes), the first ROSC ( $\geq 20$ minutes) time was defined as the CPR stop-time. The CPR duration consisted of pre-hospital CPR duration (CPR start to ED presentation) and in-hospital CPR duration (ED presentation to CPR stop).

\section{Indications and management of ECPR in the KUMC ED} The indications for ECPR in the KUMC ED during the study period were 1 ) age $\geq 18$ years; 2) sudden cardiac 
arrest with presumed correctable causes; 3) witnessed cardiac arrest with or without bystander CPR; or 4) noflow time (time interval from presumed arrest to CPR started by the EMS provider) was expected to be short, even for unwitnessed arrests. The initial cardiac arrest rhythm documented pre-hospitalization was not considered as an indication for ECPR. The contraindications for ECPR were 1) cardiac arrest due to a clearly uncorrectable cause; 2) presence of a terminal illness or malignancy; 3) suspected or confirmed traumatic origin of arrest; and 4) no informed consent from the family. The ECPR team was activated by the emergency physician in cases when OHCA patients met the inclusion criteria, and required prolonged $\mathrm{CPR}$ more than 10 minutes as in-hospital CPR duration or recurrently arrested in the ED after achievement of ROSC ( $\geq 20$ minutes). The time from activating the ECPR team to implantation of ECPR was 10 to 15 minutes during the day and 20 to 25 minutes during the night in our institution. ECPR was implemented in the ED or coronary catheterization room.

All patients who experienced cardiac arrest received advanced cardiac life support by emergency physicians according to the AHA guidelines, excluding patients with a do not attempt resuscitation (DNAR) order or irreversible signs of death. The ECPR team consisted of emergency physicians, cardiovascular surgeons, coronary intervention specialists, and perfusionists. A twin-pulse extracorporeal life support system (T-PLS : NewHeartbio, Seoul, Korea) or a Capiox emergency bypass system $\left(\mathrm{EBS}^{\oplus}\right.$; Terumo Inc., Tokyo, Japan) were used for ECPR. Depending on the patient's body size, a 15- to 17-Fr arterial and a 21 to 23-Fr venous catheter were inserted into the femoral artery and vein percutaneously using Seldinger's technique while maintaining chest compressions. The flow rate was initially set at 2.5 to $3.0 \mathrm{~L} / \mathrm{min}$. Anticoagulation with heparin was given immediately after initiation of ECLS and titrated to maintain an activated clotting time of 200 to 220 seconds.

Intra-arterial blood pressure and arterial blood gas analysis at the radial artery were monitored. An intraaortic balloon pump was not used in the ED. After implementation of ECPR, CAG was performed as soon as possible in cases of suspected acute coronary syndrome (ACS).

ECPR was discontinued if spontaneous heart beating was not obtained despite correction of the cause of cardiac arrest. Withdrawal of ECPR was considered if there was evidence of multiple organ failure, refractory shock, or irreversible neurologic injury and with consent from the patient's family. A weaning protocol was instituted after assessing hemodynamic profiles and myocardial functions by echocardiography while progressively reducing extracorporeal membrane oxygenation (ECMO) flow of $1.5 \mathrm{~L} / \mathrm{min}[15,16]$.

\section{Selection of study patients and outcome measurements} We enrolled the patients aged 18 years or older who experienced OHCA, with no traumatic origin of cardiac arrest, in the study from the CPR registry cohort. The patients who were transferred from the ED to other hospitals after ROSC and those who had missed the CPR duration date were excluded (Figure 1). The primary end point was a good neurological outcome (measured as a CPC score of 1 or 2) at 3 months post cardiac arrest [17]. The secondary end points were 24-hour survival rate, survival to discharge, and survival rate at 3 months post arrest.

\section{Data analysis}

Receiver operating characteristic (ROC) curve analysis of CPR duration was used to differentiate between favorable and unfavorable neurological outcomes in the CCPR group. We compared good neurological outcomes by using a Kaplan-Meier plot for ECPR and CCPR groups with CPR duration longer than the estimated cut off duration. A propensity-score-matching analysis was performed to reduce the effects of selection bias and possible confounding factors. The propensity score, which was the predicted probability of receiving ECPR with covariates, was derived through a logistic regression model. The covariates, including age, sex, comorbidity score, bystander CPR, witnessed cardiac arrest, first documented arrest rhythm, presumed etiology of arrest, interval from arrest to CPR started by EMS provider, CPR duration, and therapeutic hypothermia, were used in propensity-score-matching. Immediate CAG for only ACS suspected patients was not matched at propensity-matching analysis, because our patients had variable causes of cardiac arrest. ECPR and CCPR cases were matched by their propensity score in blocks of 1:1 and the selected patients formed wellmatched 1:1 pairs in both groups $[15,16]$. Model discrimination was assessed with $C$ statistics. We compared the characteristics according to the good neurologic outcome to find prognostic factors in matched ECPR group.

The data were reported as median with interquartile range (IQR). Continuous variables were compared using the Mann-Whitney test. Categorical variables were compared using the chi-square or Fisher's exact test. All statistical analyses were carried out using SPSS version 20.0 (IBMSPSS Inc., Chicago, IL, USA) with the propensityscore-matching program. Two-tailed $P$-values $\mathrm{f}<0.05$ were considered statistically significant.

\section{Results}

Characteristics, CPR variables and outcomes of the unmatched ECPR and CCPR group

A total of 625 patients who received CPR due to OHCA at $\mathrm{ED}$ were registered with the CPR registry during the study period, of which 543 patients were enrolled in this 


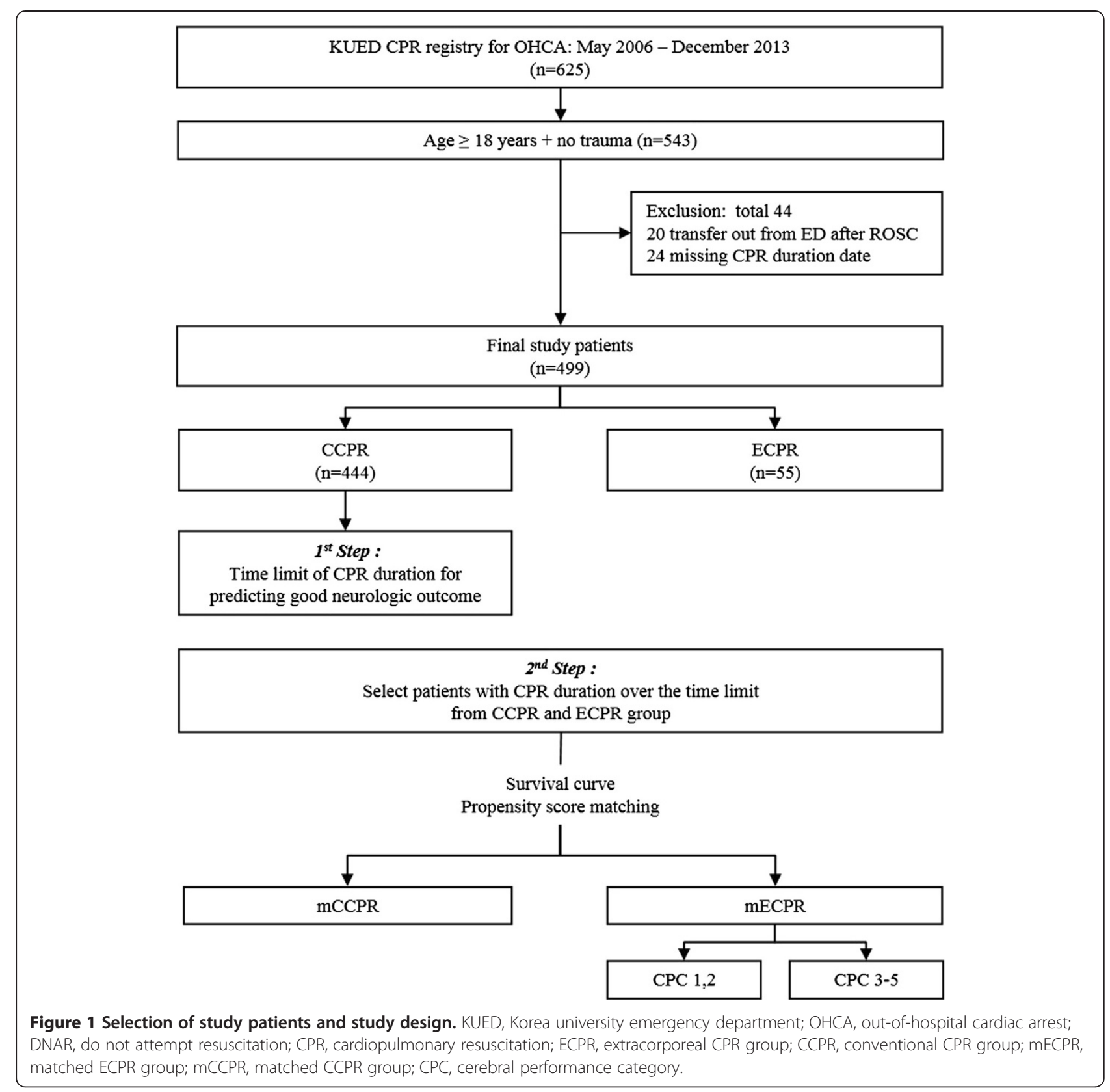

study. Of these, 499 patients were included in our study group according to the selection criteria; 444 were included in the CCPR group and 55 in ECPR group (Figure 1). The baseline characteristics and CPR variables of both groups are shown in Table 1.

Patients in the ECPR group had significantly younger age, lower comorbidity score, and higher incidence of shockable rhythm as the first documented arrest rhythm than those in the CCPR group. The CPR duration and the incidence of presumed etiology of cardiac arrest was longer and higher in the ECPR than in the CCPR group (Table 1). A good neurological outcome at 3 months post arrest did not show any significant difference between groups (Table 1).

The trend of outcomes according to the CPR duration in both unmatched groups

The rates of ROSC or ROSB, 24-hour survival, survival rate at 3 months post cardiac arrest, and good neurological outcome (CPC 1,2) at 3 months post arrest tended to decrease more sharply in the CCPR than in the ECPR group according to the prolongation of $\mathrm{CPR}$ duration (Figure 2). 
Table 1 Comparison of characteristics between the ECPR group and CCPR group

\begin{tabular}{|c|c|c|c|}
\hline & ECPR $(n=55)$ & CCPR $(n=444)$ & $P$-value \\
\hline Age, years & 53 (41 to 68$)$ & 69 (56 to 77$)$ & $<0.001$ \\
\hline Male : female, $\mathrm{n}$ & $41: 14$ & $285: 159$ & 0.136 \\
\hline \multicolumn{4}{|l|}{ Pre-existing comorbidity, n (\%) } \\
\hline Hypertension & $14(25.5)$ & $161(36.3)$ & 0.134 \\
\hline Cardiovascular disease & $15(27.3)$ & $101(22.7)$ & 0.498 \\
\hline Chronic pulmonary disease & $1(1.8)$ & $33(7.4)$ & 0.157 \\
\hline Neurologic disease & $3(5.5)$ & $67(15.1)$ & 0.062 \\
\hline Chronic liver disease & $1(1.8)$ & $20(4.5)$ & 0.495 \\
\hline Chronic kidney disease & $1(1.8)$ & $41(9.2)$ & 0.070 \\
\hline Diabetes & $11(20.0)$ & $122(27.5)$ & 0.262 \\
\hline Malignancy & $1(1.8)$ & $38(8.6)$ & 0.106 \\
\hline Number of pre-existing comorbidities & $0(0$ to 1$)$ & $1(0$ to 2$)$ & 0.003 \\
\hline Comorbidity score & 0 (0 to 1$)$ & 1 (0 to 2$)$ & $<0.001$ \\
\hline Witnessed, n (\%) & $43(78.2)$ & $328(73.9)$ & 0.623 \\
\hline Bystander CPR, n (\%) & $23(41.8)$ & $151(34.0)$ & 0.294 \\
\hline First documented arrest rhythm, n (\%) & & & $<0.001$ \\
\hline VFNT & $31(56.4)$ & $85(19.1)$ & \\
\hline PEA & $10(18.2)$ & $91(20.5)$ & \\
\hline Asystole & $14(25.5)$ & $268(60.4)$ & \\
\hline Arrest to CPR start, minutes & 7 (0 to 13) & $8(5$ to 12$)$ & 0.108 \\
\hline CPR duration, minutes & $62(47$ to 89$)$ & 35 (21 to 50$)$ & $<0.001$ \\
\hline Pre-hospital CPR duration & $13(7$ to 17$)$ & $13(8$ to 17$)$ & 0.930 \\
\hline In-hospital CPR duration & 47 (35 to 80$)$ & 21 (8 to 35$)$ & $<0.001$ \\
\hline Presumed etiology of arrest, $\mathrm{n}(\%)$ & & & $<0.001$ \\
\hline Cardiac & $49(89.1)$ & $277(62.4)$ & \\
\hline Non-cardiac & $6(10.9)$ & $167(37.6)$ & \\
\hline \multicolumn{4}{|l|}{ At the time of admission to ED } \\
\hline SAPS $\|^{*}$ & 91 (87 to 97) & 97 (91 to 103) & $<0.001$ \\
\hline Arterial $\mathrm{pH}^{*}$ & $6.98(6.86$ to 7.05$)$ & $6.94(6.83$ to 7.06$)$ & 0.473 \\
\hline Serum lactate* & 11.7 (8.8 to 16.0$)$ & $10.8(7.3$ to 14.0$)$ & 0.083 \\
\hline Any ROSC events during CPR, n (\%) & $17(30.9)$ & $94(21.2)$ & 0.121 \\
\hline Therapeutic hypothermia, n (\%) & $17(30.9)$ & $71(16.0)$ & 0.013 \\
\hline ROSB/ROSC, n (\%) & $44(80.0)$ & $212(47.7)$ & $<0.001$ \\
\hline Survival to 24 hours, n (\%) & $32(58.2)$ & $138(31.1)$ & $<0.001$ \\
\hline CPC score at discharge & & & 0.226 \\
\hline $1, \mathrm{n}(\%)$ & $7(12.1)$ & $30(6.8)$ & \\
\hline $2, \mathrm{n}(\%)$ & $1(1.8)$ & $6(1.4)$ & \\
\hline $3, \mathrm{n}(\%)$ & $0(0)$ & $8(1.8)$ & \\
\hline $4, \mathrm{n}(\%)$ & $1(1.8)$ & $42(9.5)$ & \\
\hline $5, \mathrm{n}(\%)$ & $46(83.6)$ & $358(80.6)$ & \\
\hline Hospital LOS in survival to discharge, day & $30(14$ to 60$)$ & 18 (9 to 30$)$ & 0.120 \\
\hline Survivor at 3 months after arrest, $\mathrm{n}(\%)$ & $8(14.5)$ & $44(9.9)$ & 0.346 \\
\hline CPC 1,2 at 3 months after arrest, $n(\%)$ & $8(14.5)$ & $36(8.1)$ & 0.128 \\
\hline
\end{tabular}

Data are shown as median (interquartile range) or number (\%). *Measured in 48 ECPR patients and 332 CCPR patients. CPR, cardiopulmonary resuscitation; ECPR, extracorporeal CPR; CCPR, conventional CPR; VF, ventricular fibrillation; VT, ventricular tachycardia; PEA, pulseless electrical activity; ED, emergency department; SAPS, simplified acute physiologic score; ROSB, return of spontaneous heart beat; ROSC, return of spontaneous circulation; CPC, cerebral performance category; LOS, length of stay. 


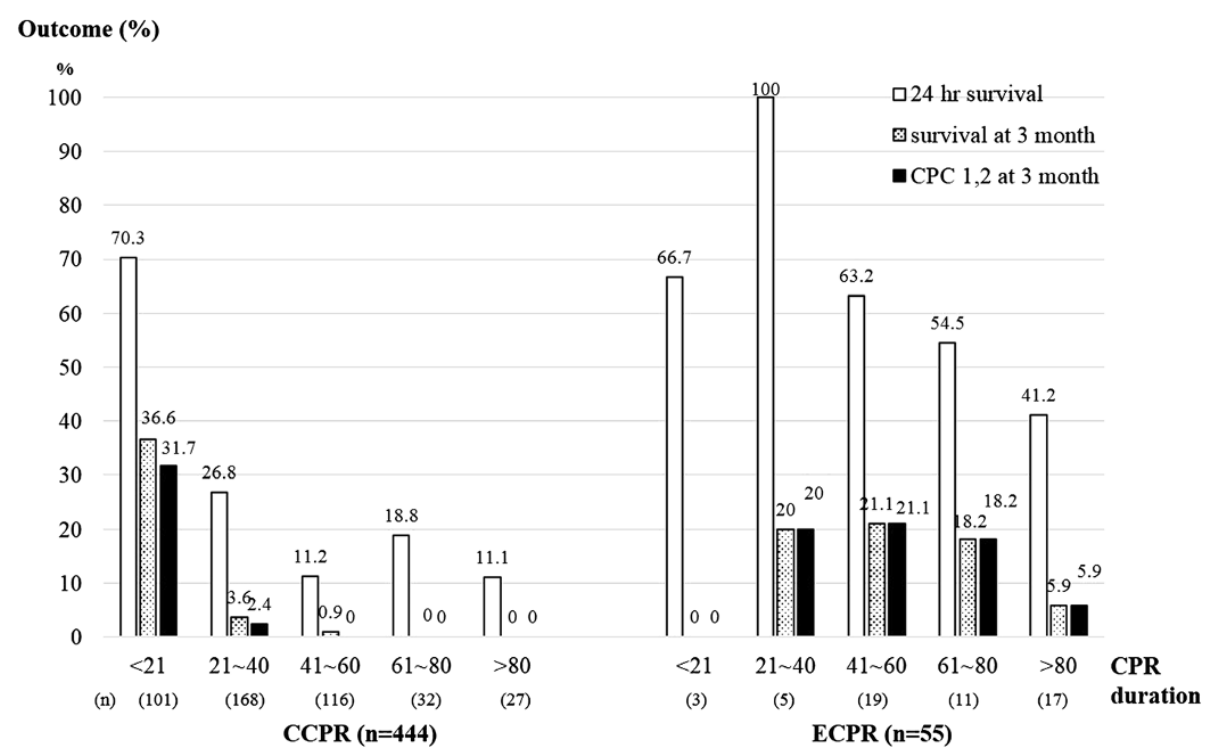

Figure 2 Trends of outcomes in the conventional cardiopulmonary resuscitation (CCPR) and extracorporeal cardiopulmonary resuscitation (ECPR) groups according to the cardiopulmonary resuscitation (CPR) duration. In the ECPR group, the longest CPR duration with a good neurologic outcome was 120 minutes. CPC, cerebral performance category.

\section{ROC curve of CPR duration to predict good neurologic} outcome in the CCPR group

Using a ROC-curve analysis of the CCPR group $(\mathrm{n}=444)$, the best discriminative CPR duration for a favorable neurological outcome was 21 minutes (area under the curve $0.925,95 \%$ CI $0.889,0.961, P<0.001$ ) (Figure 3 ).

\section{Comparison of ECPR and CCPR group survival analysis in patients with CPR duration $\geq 21$ minutes}

Survival analysis using a Kaplan-Meier plot showed more favorable neurological outcomes in the ECPR than in the CCPR group at 3 months post cardiac arrest among patients with a CPR duration $\geq 21$ minutes (stratified logrank test, $P<0.001$ ) (Figure 4).

\section{Outcome analysis of propensity-score-matched groups} (in cases of CPR duration $\geq 21$ minutes)

The $c$-statistic of the propensity-score model was 0.999, and the median propensity scores in the ECPR and CCPR groups were 0.39 (SD 0.14) versus 0.10 (SD 0.14), respectively, before matching and 0.39 (SD 0.20) versus 0.34 (SD 0.20), respectively, after matching (Figure 5). The confounding factors of the characteristics were balanced and there were no significant differences in the matched groups (Table 2). The median value of CPR duration was 63 minutes (IQR 50 to 88 ) and 61 minutes (IQR 40 to 84 ) in the matched ECPR group (mECPR) and the matched CCPR group (mCCPR), respectively. Application of therapeutic hypothermia $(\mathrm{TH})$ was not different between $\mathrm{mECPR}$ and $\mathrm{mCCPR}(P=0.821)$. CAG for suspected acute coronary disease was more frequent in $\mathrm{mECPR}$ than
mCCPR $(P=0.213)$ (Table 3). The rate of 24-hour survival and a favorable neurological outcome at 3 months post cardiac arrest in the mECPR group were significantly higher than those in the mCCPR group, although the rate of survival to discharge was similar in both groups (Figure 6).

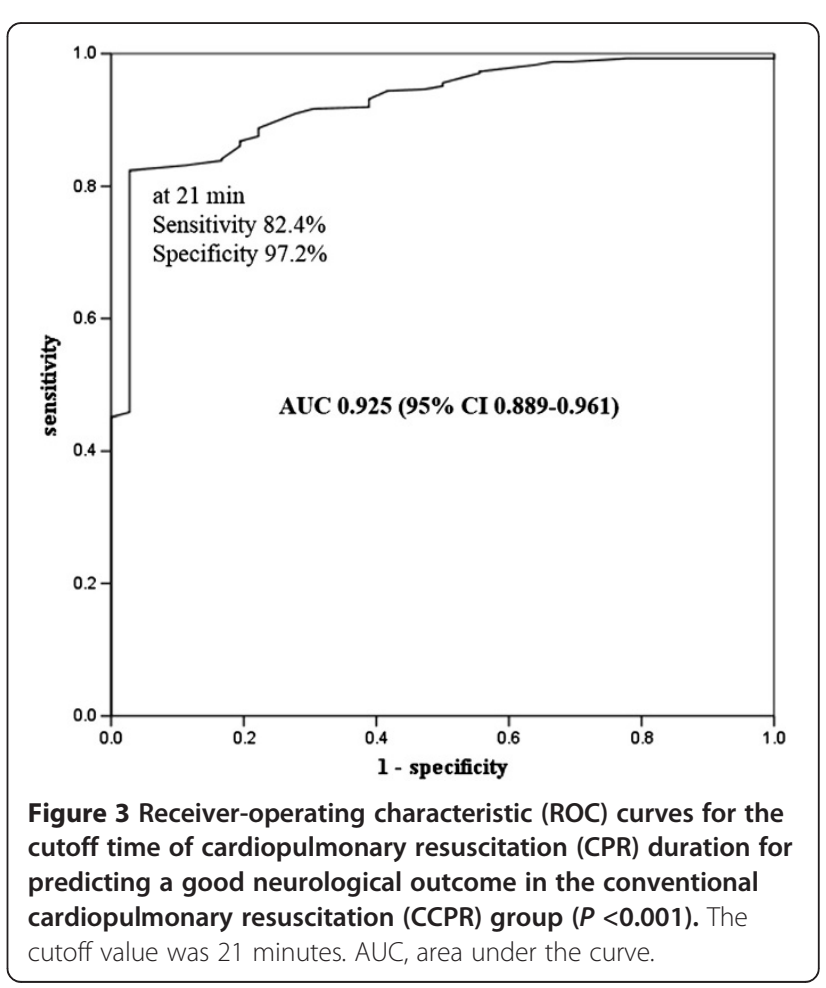




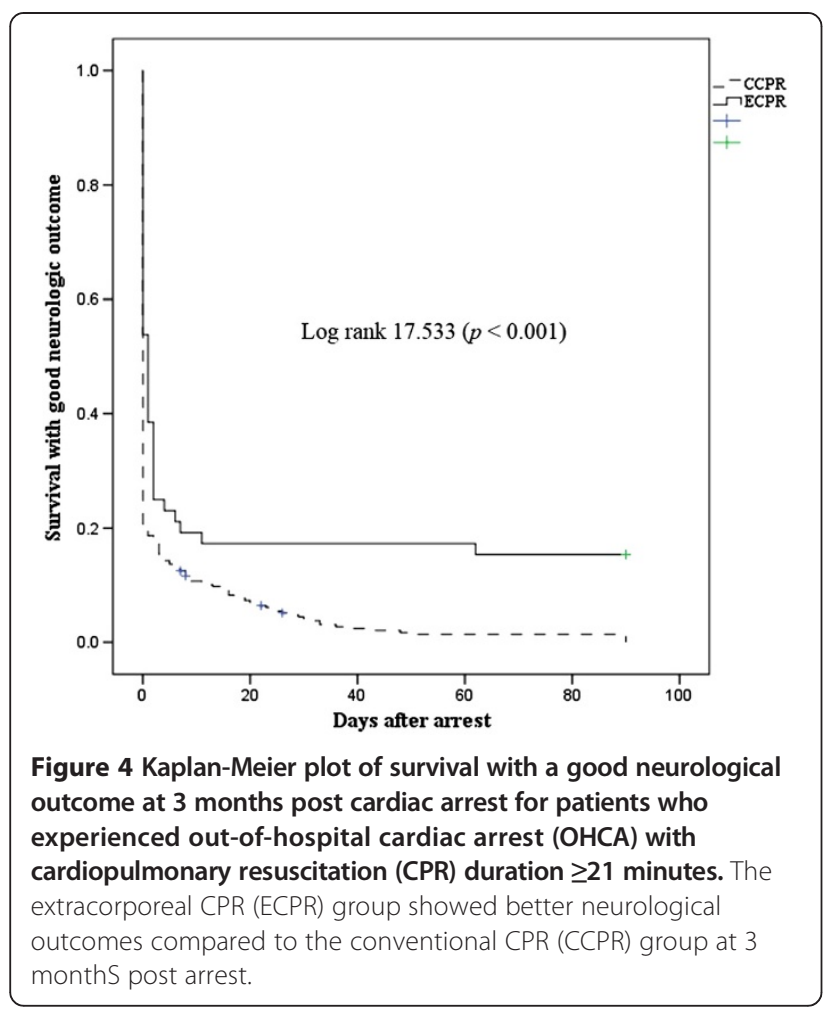

\section{Comparison of CPR data according to the neurologic outcome in the $\mathrm{mECPR}$ group}

Of $52 \mathrm{mECPR}$ patients, 8 patients received ECPR due to recurrent cardiac arrest following ROSC ( $\geq 20$ minutes). The median CPR duration and median time interval from ROSC to ECPR implantation was 68.5 (range 32 to 136) hours and 1.5 (range 0.6 to 6.4) hours, respectively. Younger age and witnessed arrest without initial asystole were significant indicators for predicting good neurologic outcome in the mECPR group (Table 3). The CPR duration of the group with good neurologic outcome tended to be short compared with those with poor neurologic outcome $(P=0.432)$. The rates of mean arterial pressure (MAP) $\geq 60 \mathrm{mmHg}$ within 2 hours post ECPR and the application of therapeutic hypothermia were higher, and the rates of ECPR-related complications were lower in the group with $\mathrm{CPC} 1$ and 2 than in the group with CPC 3 to 5 (Table 4). Inotropic equivalent dose was higher in the group with CPC 3 to 5 than in the group with CPC 1 and 2 (Table 4) [18]. The rate of the patients without any coronary lesions was higher in the group with good neurologic outcome. (Table 5).

\section{Upper limitation of CPR duration in the ECPR implantation group for expecting a good neurologic outcome}

Because there was no significant difference in CPR duration between good neurologic outcome and poor outcome in the mECPR group (Table 3), we compared neurologic outcomes in the $\mathrm{mECPR}$ and $\mathrm{mCCPR}$ groups

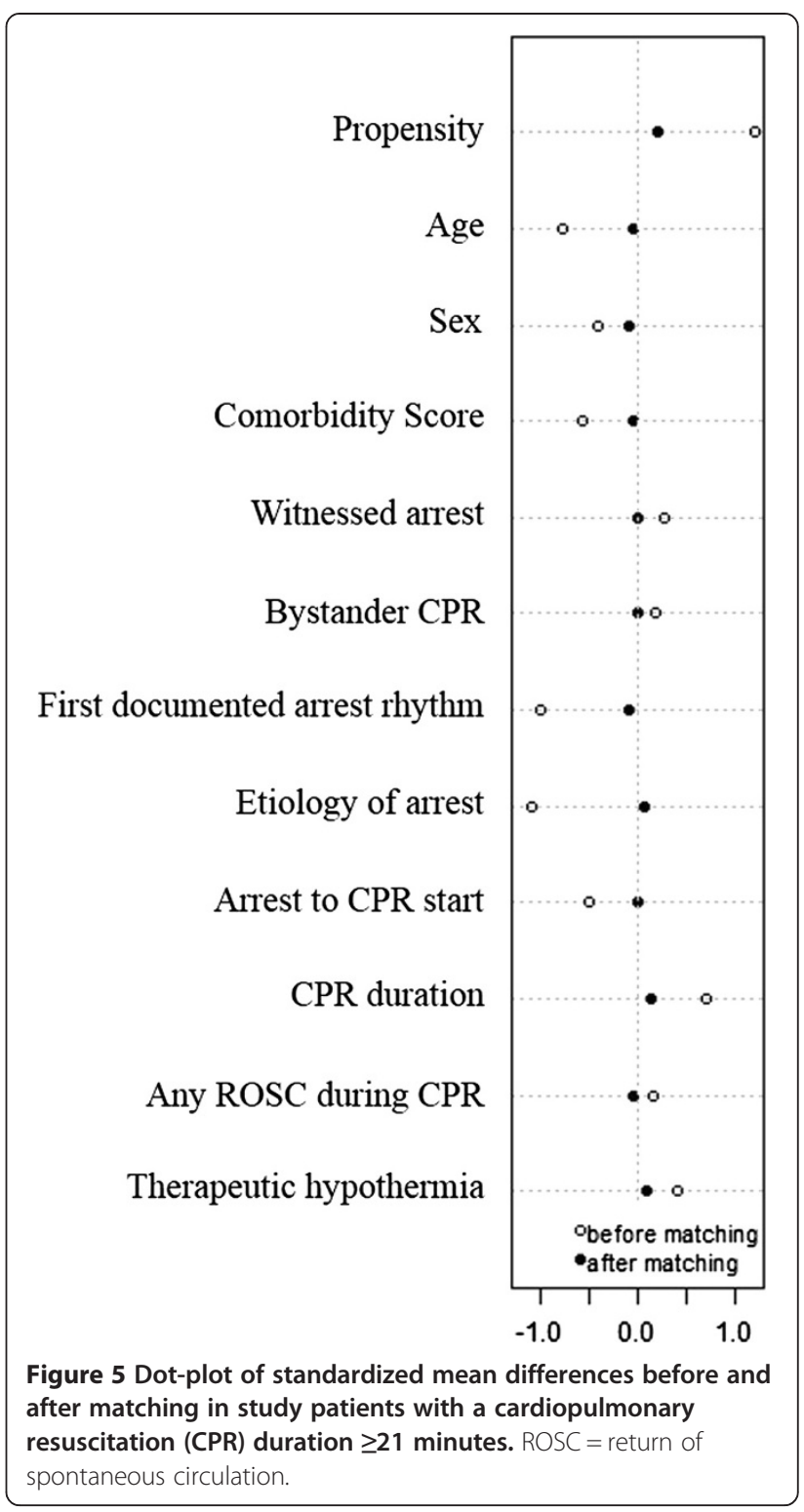

according to the CPR duration (Figure 7). There was no difference in neurological outcome between MECPR and mCCPR when the CPR duration was 21 to 40 minutes. However, mECPR showed a higher rate of good neurological outcomes with 21 to 80 minutes of CPR duration than $\operatorname{mCCPR}(P=0.026)$.

\section{Discussion}

This study is one of the few using propensity score for evaluating the impact of ECPR for OHCA. In this study the CCPR group tended to show decreased rates of ROSC, 24-hour survival, survival and good neurological outcome at 3 months post cardiac arrest as the CPR duration increased. In particular, the rate of good neurological outcomes significantly decreased after CPR duration of 21 minutes. The survival analysis for the OHCA patients 
Table 2 Comparison of the characteristics between the mECPR and mCCPR groups

\begin{tabular}{|c|c|c|c|}
\hline & mECPR $(n=52)$ & $\operatorname{mCCPR}(n=52)$ & $P$-value \\
\hline Age, years & 54 (41 to 69$)$ & 54 (42 to 68$)$ & 0.871 \\
\hline Male : female, $n$ & $40: 12$ & $38: 14$ & 0.821 \\
\hline \multicolumn{4}{|l|}{ Pre-existing comorbidity, n (\%) } \\
\hline Hypertension & $13(25.0)$ & $12(23.1)$ & 1.000 \\
\hline Cardiovascular disease & $15(28.8)$ & $11(21.2)$ & 0.497 \\
\hline Chronic pulmonary disease & $1(1.9)$ & $0(0.0)$ & 1.000 \\
\hline Neurologic disease & $3(5.8)$ & $4(7.7)$ & 1.000 \\
\hline Chronic liver disease & $1(1.9)$ & $2(3.8)$ & 1.000 \\
\hline Chronic kidney disease & $1(1.9)$ & $3(5.8)$ & 0.618 \\
\hline Diabetes & $11(21.2)$ & $6(11.5)$ & 0.289 \\
\hline Malignancy & $1(1.9)$ & $2(3.8)$ & 1.000 \\
\hline Number of pre-existing comorbidities & 1 (0 to 2$)$ & $1(0$ to 1$)$ & 0.695 \\
\hline Comorbidity score & $0(0$ to 1$)$ & $0(0$ to 1$)$ & 0.692 \\
\hline Witnessed, n (\%) & $42(80.8)$ & $42(80.8)$ & 1.000 \\
\hline Bystander CPR, n (\%) & $22(42.3)$ & $22(30.8)$ & 1.000 \\
\hline First documented arrest rhythm, n (\%) & & & 0.639 \\
\hline VFNT & $31(59.6)$ & $29(55.8)$ & \multirow[t]{3}{*}{0.901} \\
\hline PEA & $8(15.4)$ & $8(15.4)$ & \\
\hline Asystole & $13(25.0)$ & $15(28.8)$ & \\
\hline Arrest to CPR start, minutes & 7.0 (0.3 to 12.8$)$ & 7.0 (5.0 to 10.0$)$ & 0.507 \\
\hline CPR duration, minutes & $62.5(49.0$ to 88.0$)$ & 60.5 (40.0 to 83.5) & 0.387 \\
\hline Pre-hospital CPR duration & $13.0(7.0$ to 17.0$)$ & $13.0(9.3$ to 16.8$)$ & 0.677 \\
\hline In-hospital CPR duration & 47.5 (35.3 to 76.8$)$ & 48.0 (25.3 to 71.0$)$ & 0.550 \\
\hline Presumed etiology of arrest, n (\%) & & & 1.000 \\
\hline Cardiac & $49(94.2)$ & $49(94.2)$ & \\
\hline Suspected ACS & $44(84.6)$ & $46(88.5)$ & \\
\hline Non-cardiac & $3(5.8)$ & $3(5.8)$ & \\
\hline \multicolumn{4}{|l|}{ At the time of admission to ED } \\
\hline SAPS $\|^{*}$ & 91 (87 to 98) & 91 (88 to 96$)$ & 0.695 \\
\hline Arterial $\mathrm{pH}^{*}$ & $6.98(6.86$ to 7.05$)$ & 6.97 (6.90 to 7.05$)$ & 0.487 \\
\hline Serum lactate* & $11.6(8.6$ to 15.3$)$ & $10.8(8.8$ to 15.0$)$ & 0.460 \\
\hline Any ROSC events during CPR, $\mathrm{n}(\%)$ & $16(30.8)$ & $17(32.7)$ & 1.000 \\
\hline
\end{tabular}

with CPR duration $\geq 21$ minutes showed a better neurological outcome at 3 months post arrest in the ECPR compared to the CCPR group. Using propensity-score matching, the mECPR group, compared with the mCCPR group showed an improved neurological outcome at 3 months post arrest, despite the survival to discharge rate not showing any difference between groups. In the mECPR group, younger age patients, with witnessed cardiac arrest, who had no asystole as an initial arrest rhythm, were good candidates for ECPR. In addition, early achievement of mean arterial pressure (MAP) $\geq 60 \mathrm{mmHg}$, therapeutic hypothermia, and low incidence of ECPRrelated complications were significant factors for good neurologic outcome in the mECPR group.

As the CCPR duration becomes longer, optimal perfusion cannot be maintained until the underlying cardiac defect is corrected. Consequently, prolonged CPR is associated with a poor outcome $[1,2,15,19,20]$. Our study showed that the probability of survival to discharge, especially with a good neurological outcome tends to decrease with longer CPR duration in the CCPR group. 
Table 3 Comparison of post-resuscitation care and outcomes between the mECPR and mCCPR groups

\begin{tabular}{|c|c|c|c|}
\hline & $\operatorname{mECPR}(n=52)$ & mCCPR $(n=52)$ & $P$-value \\
\hline Rate of ROSB/ROSC ( $\geq 20$ minutes), $n$ (\%) & $42(80.8)$ & $20(38.5)$ & $<0.001$ \\
\hline Therapeutic hypothermia, n (\%) & $14(26.9)$ & $12(23.1)$ & 0.821 \\
\hline CAG in patients with suspected ACS (\%) & 39 in 44 (88.6) & 11 in $15(73.3)^{*}$ & 0.213 \\
\hline CAG findings & $n=39$ & $n=11$ & 0.010 \\
\hline No significant coronary lesion & $5(12.8)$ & $4(36.4)$ & \\
\hline Coronary spasm & $3(7.7)$ & $4(36.4)$ & \\
\hline Presence of coronary occlusion/stenosis, n (\%) & $31(79.5)$ & $3(27.3)$ & \\
\hline Diseased coronary artery, n (\%) & $n=31$ & $n=3$ & 0.603 \\
\hline 1 vessel & $23(74.2)$ & $3(100)$ & \\
\hline 2 vessels & $5(16.1)$ & $0(0)$ & \\
\hline 3 vessels & $3(9.7)$ & $0(0)$ & \\
\hline PCl for coronary occlusion/stenosis & $29(93.5)$ & $3(100)$ & 1.000 \\
\hline CPC score at discharge & & & 0.011 \\
\hline $1, \mathrm{n}(\%)$ & $7(13.5)$ & $1(1.9)$ & \\
\hline $2, \mathrm{n}(\%)$ & $1(1.9)$ & 0 & \\
\hline $3, \mathrm{n}(\%)$ & 0 & $2(3.8)$ & \\
\hline $4, \mathrm{n}(\%)$ & $1(1.9)$ & $8(15.4)$ & \\
\hline $5, \mathrm{n}(\%)$ & $43(82.7)$ & $41(78.8)$ & \\
\hline Hospital LOS in survival to discharge, days & $30(14$ to 60$)$ & $28(16$ to 50$)$ & 0.766 \\
\hline CPC score at 3 months post arrest & & & 0.070 \\
\hline $1, \mathrm{n}(\%)$ & $7(13.5)$ & $1(1.9)$ & \\
\hline $2, n(\%)$ & $1(1.9)$ & $0(0)$ & \\
\hline $3, \mathrm{n}(\%)$ & $0(0)$ & $2(3.8)$ & \\
\hline $4, \mathrm{n}(\%)$ & $0(0)$ & $1(1.9)$ & \\
\hline $5, \mathrm{n}(\%)$ & $44(84.6)$ & $48(92.3)$ & \\
\hline Final diagnosis of arrest, $\mathrm{n}(\%)$ & & & $<0.001$ \\
\hline \multicolumn{4}{|l|}{ Cardiac } \\
\hline ACS/AMI & $36(69.2)$ & $9(17.3)$ & \\
\hline Lethal arrhythmia & $3(5.8)$ & $5(9.6)$ & \\
\hline $\mathrm{HF}, \mathrm{HCMP}, \mathrm{DCMP}$ & $3(5.8)$ & $2(3.8)$ & \\
\hline Pulmonary embolism & $2(3.8)$ & $1(1.9)$ & \\
\hline Unknown sudden arrest & $4(7.7)$ & $31(59.6)$ & \\
\hline \multicolumn{4}{|l|}{ Non-cardiac } \\
\hline Respiratory arrest & $1(1.9)$ & $0(0)$ & \\
\hline Hypothermia & $1(1.9)$ & $0(0)$ & \\
\hline Acute kidney injury & $1(1.9)$ & $3(5.8)$ & \\
\hline Brain hemorrhage & $1(1.9)$ & $1(1.9)$ & \\
\hline Causes of death at 3 months post arrest, n (\%) & $n=44$ & $n=48$ & $<0.001$ \\
\hline No ROSB or ROSC & $10(22.7)$ & $32(66.7)$ & \\
\hline Refractory shock & $24(54.5)$ & $4(8.4)$ & \\
\hline Hypoxic brain injury and organ failure & $8(18.2)$ & $12(25.0)$ & \\
\hline Brain death & $2(4.5)$ & $0(0)$ & \\
\hline
\end{tabular}

Data are shown as median (IQR) or number (\%). *In 15 suspected ACS patients with ROSC ( $\geq 20$ minutes). CPR, cardiopulmonary resuscitation; ECPR, extracorporeal CPR; CCPR, conventional CPR; ROSB, return of spontaneous heart beat; ROSC, return of spontaneous circulation; CAG, coronary angiography; $A C S$, acute coronary syndrome; PCl, percutaneous coronary intervention; CPC, cerebral performance category; LOS, length of stay; HF, heart failure; HCMP, hypertrophic cardiomyopathy; DCMP, dilated cardiomyopathy. 


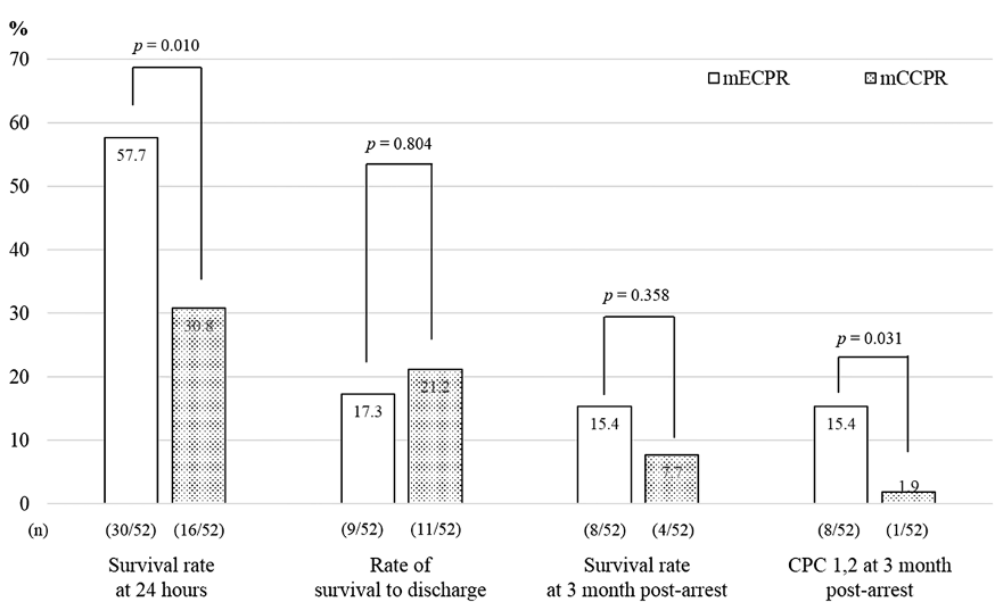

Figure 6 Outcomes of the matched extracorporeal cardiopulmonary resuscitation (mECPR) and matched conventional cardiopulmonary resuscitation $(\mathrm{mCCPR})$ groups after propensity-score-matching in patients with cardiopulmonary resuscitation (CPR) duration $\geq 21$ minutes. CPC, cerebral performance category.

In patients who experience prolonged cardiac arrest with failed CCPR, ECPR can provide an alternative therapeutic option to improve the chances of rapid return of circulation and survival with good neurological outcome $[4,14,21,22]$. Whether determining an optimal transition time of CPR duration before deploying ECPR results in a better neurological outcome than CCPR remains unknown. Reynolds et al. reported that alternative methods should be considered within 16.1 minutes of total CPR duration from chest compression by the EMS provider [1]. However, we have stepped even further and determined that 21 minutes from CPR start by the healthcare provider is an acceptable cutoff time for the CPR duration in predicting a good neurological outcome in the patients who receive only CCPR. In this study, the ECPR group showed a better neurological outcome at 3 months post arrest compared to the CCPR group in patients with a CPR duration $\geq 21$ minutes. This result was similar with the guidelines for indications for the use of ECPR by French medical scientific societies, which recommended that a refractory cardiac arrest prolonged for 30 minutes results in a poor chance of obtaining good neurological outcomes, and ECPR should be considered [14].

ECPR requires many medical resources and has several limitations; primarily, it requires adequate indications for implementation. French medical scientific societies recommended that it is not appropriate to consider extracorporeal life support when CPR has lasted less than 15 minutes [14]. In this study, a good neurological outcome occurred in $31.7 \%$ of patients in the CCPR group with a CPR duration $<21$ minutes. Three patients during our experiment received ECPR due to recurrent arrest after achievement of early ROSC ( $\geq 20$ minutes) within 20 minutes of CPR duration. However, they have all expired. The importance and advantage of CCPR during a short low-flow time (CPR duration) cannot be replaced by using ECPR.

In this study, there were no differences in the interval from cardiac arrest to CPR start and CPR duration between the group with CPC 1,2 and the group with CPC 3 to 5 among the mECPR group. Time interval from CPR start to ECPR implantation is also important to outcomes among OHCA patients who required prolonged CPR. Leick et al. reported that a door-to-ECPR implantation time of $<30$ minutes, and not just total CPR duration, had a benefit of 1-month survival in ECPR patients [23]. Fagnoul et al. reported that good outcome can be obtained in 15 to $20 \%$ of patients, provided that time from arrest to ECPR flow is shorter than 60 minutes [24]. In this study, CPR duration of 21 to 80 minutes resulted in a good neurologic outcome for $19.4 \%$ of patients in the mECPR group. If we consider ECPR as an alternative method after 21 minutes of CPR duration, the time of ECPR implantation will be after 40 minutes of CPR duration, due to the time interval from the call for team activation to ECPR implantation. The patients with CPR duration of 41 to 80 minutes showed better neurologic outcome in the mECPR than in the mCCPR group, except the one patient with the longest CPR duration of $120 \mathrm{mi}-$ nutes. This case was previously reported [25]. Our study suggests that OHCA patients who do not respond to conventional CPR given by the healthcare provider within 21 minutes must be considered for ECPR as an alternative method, and earlier implantation of ECPR may be better for expecting a good neurologic outcome, because the rate of good neurological outcomes tend to decrease as the CPR duration increases, even in the mECPR group.

Although this study focused on the CPR duration, many other covariates, including no-flow time, initial 
Table 4 Comparison of the baseline characteristics according to good neurologic outcome in the $m E C P R$ group $(n=52)$

\begin{tabular}{|c|c|c|c|}
\hline & CPC $1,2(n=8)$ & CPC 3 to $5(n=44)$ & $P$-value \\
\hline Age, years & 37 (22 to 54$)$ & 56 (43 to 70$)$ & 0.014 \\
\hline Male : female, $n$ & $7: 1$ & $33: 11$ & 0.663 \\
\hline \multicolumn{4}{|l|}{ Pre-existing comorbidity, n (\%) } \\
\hline Hypertension & $0(0)$ & $13(29.5)$ & 0.177 \\
\hline Cardiovascular disease & $2(25.0)$ & $13(29.5)$ & 1.000 \\
\hline Chronic pulmonary disease & $0(0)$ & $1(2.3)$ & 1.000 \\
\hline Neurologic disease & $0(0)$ & $1(2.3)$ & 1.000 \\
\hline Chronic liver disease & $0(0)$ & $1(2.3)$ & 1.000 \\
\hline Chronic kidney disease & $0(0)$ & $1(2.3)$ & 1.000 \\
\hline Diabetes & $1(12.5)$ & $10(22.7)$ & 1.000 \\
\hline Malignancy & $1(12.5)$ & $0(0)$ & 0.154 \\
\hline Number of pre-existing comorbidities & $0(0$ to 1$)$ & $1(0$ to 2$)$ & 0.135 \\
\hline Comorbidity score & $0(0$ to 1$)$ & $0(0$ to 1$)$ & 0.367 \\
\hline Witnessed, n (\%) & $8(100)$ & $34(77.3)$ & 0.328 \\
\hline Bystander CPR, n (\%) & $5(62.5)$ & $17(38.6)$ & 0.260 \\
\hline First documented arrest rhythm, n (\%) & & & 0.191 \\
\hline VFNT & $6(75.0)$ & $25(56.8)$ & \\
\hline PEA & $2(25.0)$ & $6(13.6)$ & \\
\hline Asystole & $0(0)$ & $13(29.5)$ & \\
\hline Arrest to CPR start, minutes & 6.0 (1.0 to 13.8$)$ & $7.0(0.3$ to 12.8$)$ & 0.794 \\
\hline CPR duration, minutes & 57.0 (52.3 to 65.8) & 67 (49 to 94) & 0.432 \\
\hline Pre-hospital duration & 14.0 (11.0 to 19.0$)$ & $13.0(6.0$ to 17.0$)$ & 0.525 \\
\hline In-hospital duration & 38.5 (31.8 to 51.0$)$ & $51.0(37.0$ to 82.5$)$ & 0.233 \\
\hline Any ROSC events during CPR & $4(50.0)$ & $12(27.3)$ & 0.231 \\
\hline \multicolumn{4}{|l|}{ At the time of admission to ED } \\
\hline SAPS $\|^{*}$ & 87 (85 to 94$)$ & 91 (88 to 98) & 0.140 \\
\hline arterial $\mathrm{pH}^{*}$ & $6.90(6.81$ to 7.04$)$ & $6.98(6.86$ to 7.05$)$ & 0.373 \\
\hline Serum lactate ${ }^{*}$ & $11.2(9.3$ to 16.5$)$ & $11.5(8.5$ to 14.9$)$ & 0.766 \\
\hline Reason for ECPR & & & 0.593 \\
\hline Refractory arrest, n (\%) & $6(75.0)$ & $38(86.4)$ & \\
\hline Recurrent arrest, n (\%) & $2(25.0)$ & $6(13.6)$ & \\
\hline \multicolumn{4}{|l|}{ Location of ECPR implantation } \\
\hline ED : catheterization room, $\mathrm{n}$ & $2: 6$ & $18: 26$ & 0.463 \\
\hline Final diagnosis of arrest, $\mathrm{n}(\%)$ & & & 0.191 \\
\hline Cardiac & $8(100)$ & $40(90.3)$ & \\
\hline ACS/AMI & $5(62.5)$ & $31(70.5)$ & \\
\hline Lethal arrhythmia & $2(25.0)$ & $1(2.3)$ & \\
\hline HF, HCMP, DCMP & $0(0)$ & $3(6.8)$ & \\
\hline Pulmonary embolism & $1(12.5)$ & $1(2.3)$ & \\
\hline Unknown sudden arrest & $0(0)$ & $4(9.1)$ & \\
\hline Non-cardiac & $0(0)$ & $4(9.1)$ & \\
\hline Respiratory arrest & $0(0)$ & $1(2.3)$ & \\
\hline Hypothermia & $0(0)$ & $1(2.3)$ & \\
\hline
\end{tabular}


Table 4 Comparison of the baseline characteristics according to good neurologic outcome in the $m E C P R$ group $(n=52)$ (Continued)

\begin{tabular}{|c|c|c|c|}
\hline Acute kidney injury & $0(0)$ & $1(2.3)$ & \\
\hline Brain hemorrhage & $0(0)$ & $1(2.3)$ & \\
\hline Witnessed + no asystole & $8(26.7)$ & $0(0)$ & 0.015 \\
\hline
\end{tabular}

arrest rhythm, causes of arrest, refractory arrest or rearrest, and post-resuscitation care will affect the good neurologic outcome from ECPR. In this study, age was a significant variable for predicting good neurologic outcome in the mECPR group. Among our neurologically intact survivors, the oldest age was 82 years in the CCPR group and 62 years in the ECPR group. Although we could not indicate the absolute age criterion for ECPR in cardiac arrest, younger age might have a more favorable outcome. Previous comorbidity is important to the outcomes of OHCA patients. In this study, there was no difference in comorbidities or SAPS II score between the groups with CPC 1, 2 and CPC 3 to 5 in the mECPR group, because we only considered patients without a serious comorbidity for ECPR.

The AHA recommended ECPR for patients who have a brief no-flow time $[8,9]$. In this study, no survivor with

Table 5 Comparison of post-ECPR care according to the neurologic outcome in the $m E C P R$ group $(n=52)$

\begin{tabular}{|c|c|c|c|}
\hline & CPC $1,2(n=8)$ & CPC 3 to $5(n=44)$ & $P$-value \\
\hline ROSB after ECPR & $8(100)$ & $34(81.0)$ & 0.328 \\
\hline MAP $\geq 60 \mathrm{mmHg}$ within 2 hrs after ECPR, $\mathrm{n}(\%)$ & $8(100)$ & $25(56.8)$ & 0.021 \\
\hline Number of infused vasopressor/inotropics, $n$ & $2(1$ to 3$)$ & $2(1$ to 2$)$ & 0.945 \\
\hline Inotropic equivalent, $\mu \mathrm{g} / \mathrm{kg} / \mathrm{min}$ for 2 hrs post ECPR & $32(10$ to 74$)$ & 59 (15 to 82$)$ & 0.180 \\
\hline LVEF after ECPR implantation & 33 (18 to 48$)$ & 10 (0 to 20$)$ & 0.009 \\
\hline Therapeutic hypothermia, n (\%) & $5(62.5)$ & $9(20.5)$ & 0.025 \\
\hline ROSB to target temperature $\left(33^{\circ} \mathrm{C}\right)$, hrs & $4(2$ to 6$)$ & 2.8 (1.6 to 3.0$)$ & 0.2220 .435 \\
\hline Time on target temperature, hrs & 24 (21 to 24$)$ & 24 (24 to 41$)$ & \\
\hline CAG in patients with suspected ACS, $n(\%)$ & 7 in 7 (100) & 32 in 37 (86.5) & 0.574 \\
\hline CAG findings & $\mathrm{n}=7$ & $n=32$ & 0.015 \\
\hline No significant coronary lesion & $2(28.6)$ & $3(9.4)$ & \\
\hline Coronary spasm, n (\%) & $0(0)$ & $3(9.4)$ & \\
\hline Coronary occlusion/stenosis, n (\%) & $5(71.4)$ & $26(81.2)$ & \\
\hline Diseased coronary artery, n (\%) & $n=5$ & $n=26$ & 0.719 \\
\hline 1 vessel & $4(80.0)$ & $19(73.1)$ & \\
\hline 2 vessels & $1(20.0)$ & $4(15.4)$ & \\
\hline 3 vessels & $0(0)$ & $3(11.5)$ & \\
\hline PCI for coronary occlusion/stenosis & $5(100)$ & $24(92.3)$ & 1.000 \\
\hline Complications during ECLS, n (\%) & $0(0)$ & $16(36.4)$ & 0.047 \\
\hline Bleeding at access site & - & $12(27.3)$ & \\
\hline Lower limb ischemia & - & $3(6.8)$ & \\
\hline Intracranial hemorrhage & - & $1(2.3)$ & \\
\hline Anterograde reperfusion catheter, n (\%) & $11(25.0)$ & $2(25.0)$ & 1.000 \\
\hline Amount of transfused pRBC & 5 (3 to 12$)$ & $5(1$ to 10$)$ & 0.833 \\
\hline Successful weaning form ECLS, n (\%) & $8(100)$ & $2(4.5)$ & $<0.001$ \\
\hline Duration of ECLS, hrs & $43.6(29.7$ to 92.8$)$ & $17.9(3.7$ to 48.7$)$ & 0.026 \\
\hline
\end{tabular}

Data are shown as median (IQR) or number (\%). CPR, cardiopulmonary resuscitation; ECPR, extracorporeal CPR; ROSB, return of spontaneous heart beat; LVEF, left ventricle ejection fraction; CAG, coronary angiography; $\mathrm{ACS}$, acute coronary syndrome; $\mathrm{PCl}$, percutaneous coronary intervention; $\mathrm{ECLS}$, extracorporeal life support; pRBC, packed red blood cells. 


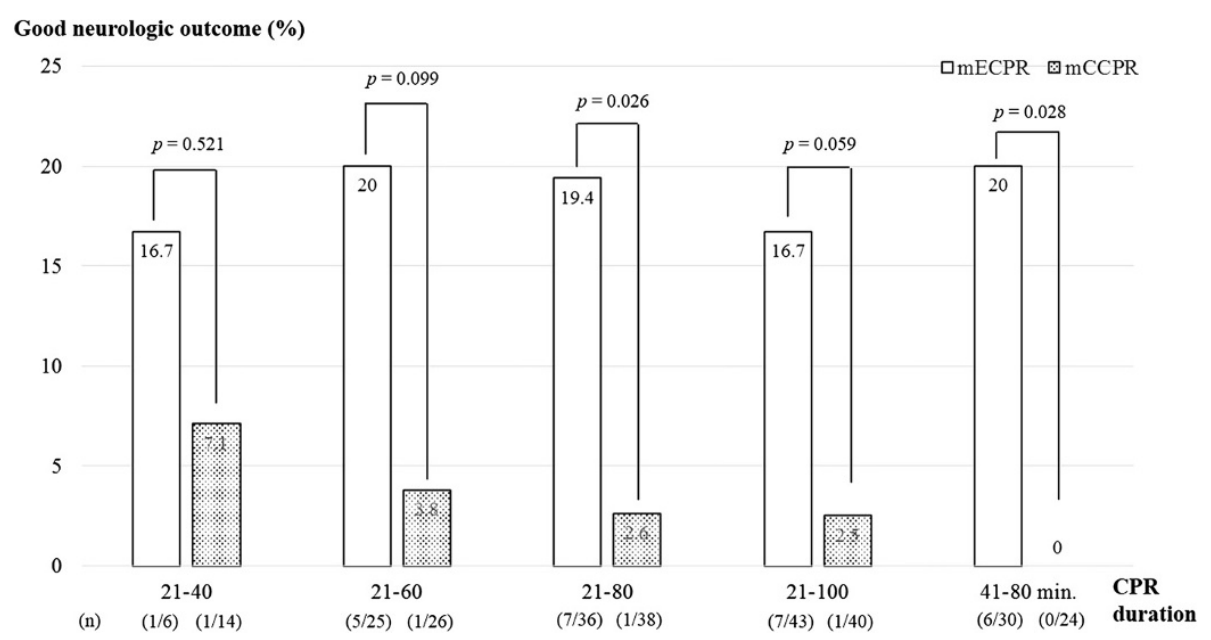

Figure 7 Comparison of the rate of good neurologic outcomes in the matched extracorporeal cardiopulmonary resuscitation (mECPR) and matched conventional cardiopulmonary resuscitation (mCCPR) groups according to the cardiopulmonary resuscitation (CPR) duration. CPR duration between 21 to 80 minutes showed that mECPR had a significantly greater rate of good neurologic outcomes (CPC 1, 2). CPC, cerebral performance category.

a good neurologic outcome was reported in ECPR patients with both asystole and unwitnessed cardiac arrest. The no-flow time may be increased among patients with unwitnessed arrest. In addition, asystole may be the last rhythm of the arrest [26]. Serum lactate or arterial pH reflects the severity of tissue hypoxia. In this study, the levels of serum lactate and arterial $\mathrm{pH}$ were not different between ECPR and CCPR (Table 1), and between groups with CPC 1, 2 group and CPC 3 to 5 in the mECPR group, respectively (Table 3 ). We have theorized that the longer time interval from arrest to ED presentation influenced the high levels of serum lactate and development of acidosis in each group.

Post-resuscitation care is also important to the outcomes of OHCA patients. Mollmann et al. reported that early invasive treatment after $\mathrm{CPR}$, irrespective of the underlying cause of cardiac arrest, leads to considerably reduced mortality and improved prognosis in patients after OHCA [27]. In our study, many patients undergoing mCCPR expired during CPR or early in the post-ROSC period. The chance of receiving immediate CAG was limited in the mCCPR group. Therefore, the incidence of coronary artery with occlusion or stenosis was lower in the mCCPR than in the mECPR group. However, most patients in the mECPR group immediately received CAG under the support of ECLS when they were suspected of having acute coronary syndrome. ECPR will enhance the opportunity for correction of the cause of cardiac arrest by supporting the essential circulation.

In this study, early achievement of hemodynamic stability after ECPR and application of therapeutic hypothermia were significant factors for good neurologic outcomes among the mECPR group: mECPR patients with CPC 3 to 5 had a high incidence of shock in spite of high-dose infusion of inotropics. We thought that this might be a result of the low incidence of ROSB and low LVEF in mECPR patients with CPC 3 to 5 . Hemodynamic instability precluded the application of therapeutic hypothermia. The most common complication during ECPR was bleeding at the access site, possibly related to the technique of catheter insertion. We used methods of sonoguided catheter insertion in the ED and fluoroscope-guided catheter insertion in the catheterization room. In this study, there was no difference in neurologic outcome according to the location of ECPR implantation in the mECPR group.

\section{Limitations}

This study has several limitations that require consideration. First, this was a non-randomized observational cohort study from retrospective analysis in a single center. Pertinent indication criteria of ECPR have not been established and the protocol has been not standardized; it differs according to the emergency medical services (EMS) and in-hospital system. All studies on ECPR, including our study, have different inclusion criteria and methods of intervention and analysis under different healthcare environments. Therefore, the transition time for considering ECPR may be changeable according to the definition of CPR duration or different EMS service system. Our study suggests that the physician who works with ECPR has to find the specific transition time for ECPR that suits their EMS system. Second, the upper limit of CPR duration for ECPR implantation was not clearly revealed in this study. The small cohort 
study prevented many parameters from achieving statistical significance. It may be necessary to perform a prospective multi-center, randomized controlled study with a clear protocol to determine the precise difference between neurological outcomes with ECPR and CCPR. Third, the standard CPR guideline has been changed during the study period. The change of guideline might affect the CPR performance in this study group. Before 2010 therapeutic hypothermia was not frequently used. Indeed, we avoided the induction of hypothermia, which could improve neurologic recovery, in ECPR patients during 2006 to 2008, because of concerns about hypothermia inducing unstable vital signs and tendency for bleeding. After the introduction of the 2010 AHA guideline, therapeutic hypothermia was more frequently applied post resuscitation in CCPR and ECPR patients [4]. Fourth, we compared the outcomes of the MECPR and the mCCPR groups under identical inclusion criteria after matching. However, several variables might not be identically matched and unmeasured bias may remain despite the use of propensity-score-matching. In this study, the incidence of $\mathrm{TH}$ in the mCCPR group was lower compared with that in the mECPR group. However, the rate of TH in patients with ROSC or ROSB was high with mCCPR compared to mECPR.

\section{Conclusions}

A good neurological outcome declined with prolonged CPR duration. ECPR should be considered as an alternative method for attaining good neurological outcomes in OHCA patients who require prolonged CPR, especially $\mathrm{CPR} \geq 21$ minutes. Younger patients, with witnessed cardiac arrest without initial asystole were good candidates for expecting good neurologic outcome from ECPR. After implantation of ECPR, early hemodynamic stabilization, prevention of ECPR-related complications, and application of therapeutic hypothermia may improve the neurologic outcome.

\section{Key messages}

- Good neurologic outcome can be expected when we transit from CCPR to ECPR, especially in patients requiring prolonged CPR, particularly for CPR duration of $\geq 21$ minutes

- Younger age patients with witnessed cardiac arrest without initial asystole were good candidates for ECPR in OHCA patients who required prolonged $C P R$

- After implantation of ECPR, early achievement of hemodynamic stability, prevention of ECPR-related complication, and therapeutic hypothermia improved the neurologic outcome

\section{Abbreviations}

ACS: acute coronary syndrome; AHA: American Heart Association; CAG: coronary angiography; CCPR: conventional cardiopulmonary resuscitation; CPC: cerebral performance category; CPR: cardiopulmonary resuscitation; DNAR: do not attempt resuscitation; ECLS: extracorporeal life support; ECMO: extracorporeal membrane oxygenation; ECPR: extracorporeal cardiopulmonary resuscitation; ED: emergency department; KUMC: Korea University Medical Center; LOS: length of stay; mCCPR: matched conventional cardiopulmonary resuscitation; mECPR: matched extracorporeal cardiopulmonary resuscitation; OHCA: out-of-hospital cardiac arrest; PCl: percutaneous coronary intervention; ROSB: return of spontaneous heart beating; ROSC: return of spontaneous circulation.

\section{Competing interests}

This work was supported by a grant funded by the College of Medicine of Korea University (grant number K1325141). Sung Woo Lee received funding from Korea University. These sources had no role in the study design, data collection, data analysis, data interpretation, or writing of the report. The authors declare that they have no competing interests. Neither the entire paper nor any part of its content has been published or has been accepted by another journal. The paper is not being submitted in its entirety or in part to any other journal.

\section{Authors' contributions}

SJK and SWL conceived and designed the study, and wrote the manuscript. JSJ, JHP, JSP, and YSH were responsible for patient care and helped conduct the trial and data collection. SJK, JSJ and SWL managed and analyzed the data, including quality control. All authors contributed substantially to the revision of the manuscript. All authors read and approved the final manuscript.

\section{Acknowledgements}

We thank the emergency physicians, cardiac surgeons, cardiology coronary specialists, and nurses at the emergency department and intensive care unit at the Korea University Medical Center. We also appreciate the statistical support of Ji-Sung Lee, PhD, at the Department of Medical Statistics.

\section{Author details}

'Department of Emergency Medicine, College of Medicine, Korea University, Inchon-ro 73, Seongbuk-gu, Seoul 136-705, Korea. ${ }^{2}$ Department of Thoracic and Cardiovascular Surgery, College of Medicine, Korea University, Seoul, Korea. ${ }^{3}$ Department of Internal Medicine, Subdivision of Cardiovascular Medicine, College of Medicine, Korea University, Seoul, Korea.

Received: 21 March 2014 Accepted: 8 September 2014

Published online: 26 September 2014

\section{References}

1. Reynolds JC, Frisch A, Rittenberger JC, Callaway CW: Duration of resuscitation efforts and functional outcome after out-of-hospital cardiac arrest: when should we change to novel therapies? Circulation 2013, 128:2488-2494

2. Sasson C, Rogers MA, Dahl J, Kellermann AL: Predictors of survival from out-of-hospital cardiac arrest: a systematic review and meta-analysis. Circ Cardiovasc Qual Outcomes 2010, 3:63-81.

3. Iwami T, Kawamura T, Hiraide A, Berg RA, Hayashi Y, Nishiuchi T, Kajino K, Yonemoto N, Yukioka H, Sugimoto H, Kakuchi H, Sase K, Yokoyama H, Nonogi $\mathrm{H}$ : Effectiveness of bystander-initiated cardiac-only resuscitation for patients with out-of-hospital cardiac arrest. Circulation 2007, 116:2900-2907.

4. Field JM, Hazinski MF, Sayre MR, Chameides L, Schexnayder SM, Hemphill R, Samson RA, Kattwinkel J, Berg RA, Bhanji F, Cave DM, Jauch EC, Kudenchuk PJ, Neumar RW, Peberdy MA, Perlman JM, Sinz E, Travers AH, Berg MD, Billi JE, Eigel B, Hickey RW, Kleinman ME, Link MS, Morrison LJ, O'Connor RE, Shuster M, Callaway CW, Cucchiara B, Ferguson JD: Part 1: executive summary: 2010 American Heart Association Guidelines for Cardiopulmonary Resuscitation and Emergency Cardiovascular Care. Circulation 2010, 2010:S640-S656.

5. Wallmuller C, Sterz F, Testori C, Schober A, Stratil P, Horburger D, Stockl M, Weiser C, Kricanac D, Zimpfer D, Deckert Z, Holzer M: Emergency 
cardio-pulmonary bypass in cardiac arrest: seventeen years of experience. Resuscitation 2013, 84:326-330.

6. Lee SW, Hong YS: Extracorporeal life-support in patients requiring CPR. Lancet 2008, 372:512-514.

7. Hajbaghery MA, Mousavi G, Akbari H: Factors influencing survival after in-hospital cardiopulmonary resuscitation. Resuscitation 2005, 66:317-321.

8. Travers AH, Rea TD, Bobrow BJ, Edelson DP, Berg RA, Sayre MR, Berg MD, Chameides L, O'Connor RE, Swor RA: Part 4: CPR overview: 2010 American Heart Association Guidelines for Cardiopulmonary Resuscitation and Emergency Cardiovascular Care. Circulation 2010, 122:S676-S684.

9. Cave DM, Gazmuri RJ, Otto CW, Nadkarni VM, Cheng A, Brooks SC, Daya M, Sutton RM, Branson R, Hazinski MF: Part 7: CPR techniques and devices: 2010 American Heart Association Guidelines for Cardiopulmonary Resuscitation and Emergency Cardiovascular Care. Circulation 2010, 122:S720-S728.

10. Angelos MG, Gaddis M, Gaddis G, Leasure JE: Cardiopulmonary bypass in a model of acute myocardial infarction and cardiac arrest. Ann Emerg Med 1990, 19:874-880.

11. Maekawa K, Tanno K, Hase M, Mori K, Asai Y: Extracorporeal cardiopulmonary resuscitation for patients with out-of-hospital cardiac arrest of cardiac origin: a propensity-matched study and predictor analysis. Crit Care Med 2013, 41:1186-1196.

12. Jacobs I, Nadkarni V, Bahr J, Berg RA, Billi JE, Bossaert L, Cassan P, Coovadia A, D'Este K, Finn J, Halperin H, Handley A, Herlitz J, Hickey R, Idris A, Kloeck W, Larkin GL, Mancini ME, Mason P, Mears G, Monsieurs K, Montgomery W, Morley P, Nichol G, Nolan J, Okada K, Perlman J, Shuster M, Steen PA, Sterz $\mathrm{F}$ : Cardiac arrest and cardiopulmonary resuscitation outcome reports: update and simplification of the Utstein templates for resuscitation registries: a statement for healthcare professionals from a task force of the International Liaison Committee on Resuscitation (American Heart Association, European Resuscitation Council, Australian Resuscitation Council, New Zealand Resuscitation Council, Heart and Stroke Foundation of Canada, InterAmerican Heart Foundation, Resuscitation Councils of Southern Africa). Circulation 2004, 110:3385-3397.

13. Charlson ME, Pompei P, Ales KL, Mackenzie CR: A new method of classifying prognostic comorbidity in longitudinal studies: development and validation. J Chron Dis 1987, 40:373-383.

14. French Ministry of Health: Guidelines for indications for the use of extracorporeal life support in refractory cardiac arrest. Ann Fr Anesth Reanim 2009, 28:182-190.

15. Chen YS, Lin JW, Yu HY, Ko WJ, Jerng JS, Chang WT, Chen WJ, Huang SC, Chi NH, Wang CH, Chen LC, Tsai PR, Wang SS, Hwang JJ, Lin FY: Cardiopulmonary resuscitation with assisted extracorporeal life-support versus conventional cardiopulmonary resuscitation in adults with in-hospital cardiac arrest: an observational study and propensity analysis. Lancet 2008, 372:554-561.

16. Shin $T G$, Choi JH, Jo IJ, Sim MS, Song HG, Jeong YK, Song YB, Hahn JY, Choi SH, Gwon HC, Jeon ES, Sung K, Kim WS, Lee YT: Extracorporeal cardiopulmonary resuscitation in patients with inhospital cardiac arrest: A comparison with conventional cardiopulmonary resuscitation. Crit Care Med 2011, 39:1-7.

17. Prohl J, Rother J, Kluge S, de Heer G, Liepert J, Bodenburg S, Pawlik K, Kreymann G: Prediction of short-term and long-term outcomes afte cardiac arrest: a prospective multivariate approach combining biochemical, clinical, electrophysiological, and neuropsychological investigations. Crit Care Med 2007, 35:1230-1237.

18. Chen YS, Ko WJ, Chi NH, Wu IH, Huang SC, Chen RJ, Chou NK, Hsu RB, Lin FY, Wang SS, Chu SH, Yu HY: Risck factor screening scale to optimize treatment for potential heart transplant candidates under extracorporeal membrane oxygenation. Am J Transplant 2004, 4:1818-1825.

19. Andreka P, Frenneaux MP: Haemodynamics of cardiac arrest and resuscitation. Curr Opin Crit Care 2006, 12:198-203.

20. Athanasuleas $C L$, Buckberg GD, Allen BS, Beyersdorf F, Kirsh MM: Sudden cardiac death: directing the scope of resuscitation towards the heart and brain. Resuscitation 2006, 70:44-51.

21. Massetti M, Tasle M, Le Page O, Deredec R, Babatasi G, Buklas D, Thuaudet $S$, Charbonneau P, Hamon M, Grollier G, Gerard JL, Khayat A: Back from irreversibility: extracorporeal life support for prolonged cardiac arrest. Ann Thorac Surg 2005, 79:178-183.

22. Chen YS, Chao A, Yu HY, Ko WJ, Wu IH, Chen RJ, Huang SC, Lin FY, Wang SS: Analysis and results of prolonged resuscitation in cardiac arrest patients rescued by extracorporeal membrane oxygenation. J Am Coll Cardiol 2003, 41:197-203.

23. Leick J, Liebetrau C, Szardien S, Fischer-Rasokat U, Willmer M, van Linden A, Blumenstein J, Nef H, Rolf A, Arlt M, Walther T, Hamm C, Mollmann H: Door-to-implantation time of extracorporeal life support systems predicts mortality in patients with out-of-hospital cardiac arrest. Clin Res Cardiol 2013, 102:661-669.

24. Fagnoul D, Combes A, De Backer D: Extracorporeal cardiopulmonary resuscitation. Curr Opin Crit Care 2014, 20:259-265.

25. Shin JS, Lee SW, Han GS, Jo WM, Choi SH, Hong YS: Successful extracorporeal life support in cardiac arrest with recurrent ventricular fibrillation unresponsive to standard cardiopulmonary resuscitation. Resuscitation 2007, 73:309-313.

26. Nadkarni VM, Larkin GL, Peberdy MA, Carey SM, Kaye W, Mancini ME, Nichol G, Lane-Truitt T, Potts J, Ornato JP, Berg RA: First documented rhythm and clinical outcome from in-hospital cardiac arrest among children and adults. JAMA 2006, 295:50-57.

27. Mollmann H, Szardien S, Liebetrau C, Elsasser A, Rixe J, Rolf A, Nef H, Weber M, Hamm C: Clinical outcome of patients treated with an early invasive strategy after out-of-hospital cardiac arrest. J Int Med Res 2011, 39:2169-2177

\section{doi:10.1186/s13054-014-0535-8}

Cite this article as: Kim et al: An optimal transition time to extracorporeal cardiopulmonary resuscitation for predicting good neurological outcome in patients with out-of-hospital cardiac arrest: a propensity-matched study. Critical Care 2014 18:535.

\section{Submit your next manuscript to BioMed Central and take full advantage of:}

- Convenient online submission

- Thorough peer review

- No space constraints or color figure charges

- Immediate publication on acceptance

- Inclusion in PubMed, CAS, Scopus and Google Scholar

- Research which is freely available for redistribution 